\title{
Coupling of Fischer-Tropsch reaction kinetics, enhanced vapor-liquid flash calculation and residence time distribution modeling for time-dependent product determination in load-flexible plants
}

\author{
Marcel Loewert, Victor Zaghini Francesconi, Lucas Tim Brübach, Peter Pfeifer* \\ Institute for Micro Process Engineering (IMVT), Karlsruhe Institute of Technology (KIT), 76344 Eggenstein-Leopoldshafen, Germany
}

\section{H I G H L I G H T S}

- FT reaction kinetics were adopted to description of a pilot-scale microchannel reactor.

- Product condensation was matched by non-ideal vapor-liquid equilibrium calculations.

- Residence time distribution models were developed for all FTS plant components.

- Time-dependent product composition under dynamic FTS operation are described.

\section{A R T I C L E I N F O}

\section{Keywords:}

Fischer-Tropsch synthesis

Microstructured reactors

Vapor-liquid flash calculation

Reaction kinetics

Residence time distribution

Dynamic synthesis

\begin{abstract}
A B S T R A C T
Fischer-Tropsch synthesis may be a solution for converting volatile renewable energies into storable liquid fuel. Microstructured reactors have been proven to cope with varying operation conditions and are able to adapt to fluctuations in this circumstance. In this regard, a suitable kinetic model for chemical synthesis is essential for the prediction of reactor and catalyst behavior. The assessment and description of the reactor and plant response during dynamic operation must also be considered to develop a control system for varying operating conditions. In this work, a time-resolved model for the description of relevant processes inside a pilot scale microstructured Fischer-Tropsch reactor and the associated test rig including the product condensation stages is presented. A residence time distribution model describes flow and mixing behavior for all system components. Time and temperature-dependent product concentration in the product traps is determined by vapor-liquid-equilibrium calculation. Phase equilibria models with ideal and real phase behavior assumptions are compared. A microkinetic model was adapted with good agreement to a variety of experimental data. When coupled, the overall model is able to predict time-resolved product characteristics based on process conditions and feed only. This mathematical description may be of use for decentralized plants in the future.
\end{abstract}

\section{Introduction}

Crude oil, natural gas and coal are still main sources of energy for transportation, industrial production and heat supply [1]. The resulting $\mathrm{CO}_{2}$ emissions contribute to anthropogenic climate change. For this reason, it is imperative that energy generation becomes $\mathrm{CO}_{2}$-neutral in the future by use of renewable energy sources.

Wind and solar power are temporally and spatially distributed. Thus, solutions for an efficient and flexible energy system are required beyond smart grids. In order to enable sector coupling, Power-to-X technology (PtX) represents a promising concept and may foster the role of electrical energy as primary energy [2]. PtX summarizes technologies that allow energy storage in forms of chemical compounds such as hydrocarbons and supply of other sectors.

Amongst P2X approaches, the Power-to-Liquid (PtL) process produces liquid energy carriers. In the short and medium term, it may not be possible to fully decarbonize the mobility and heat sectors, i.e. to decouple them from the use of fossil fuels and to cover national or global energy requirements entirely on an electrical basis [1]. On the long term, long-distance traffic will depend on liquid fuels with high energy density. According to recent studies, transport will depend due to economic and grid stability with around $50 \%$ on P2X in Germany in

\footnotetext{
* Corresponding author.

E-mail addresses: marcel.loewert@ineratec.de (M. Loewert), uhesz@student.kit.edu (V.Z. Francesconi), lucas.bruebach@kit.edu (L.T. Brübach), peter.pfeifer@kit.edu (P. Pfeifer).
} 
2050 [3].

One possible process pathway for PtL is the Fischer-Tropsch Synthesis (FTS). It is a strongly exothermic, heterogeneously catalyzed process for the generation of liquid hydrocarbons from synthesis gas (hydrogen and carbon monoxide). Hydrogen can be obtained from electrolysis, while $\mathrm{CO}$ can be derived from various regenerative and thus $\mathrm{CO}_{2}$-neutral sources. Examples are biomass digestion or gasification and $\mathrm{CO}_{2}$ direct air capture. $\mathrm{CO}_{2}$ must be reduced to $\mathrm{CO}$, which is possible by reverse water gas shift (RWGS) or an electrochemical process. The target products are typically liquid fuels such as gasoline, kerosene and diesel, but also industrial intermediates such as alkenes (olefins) and paraffinic waxes. Fuels produced in the chain length range of diesel have a high Cetane number and improved combustion properties. They are free of aromatics and other heteroatoms such as sulfur and nitrogen which leads to lower soot formation and overall emissions upon combustion [4].

In order to provide an efficient reactor technology for FTS and other reaction processes, microstructured reactors have been developed, investigated and optimized. Due to thin fluid layers in such microstructures, heat transfer and mass transfer in the reaction zone are intensified. This results in a considerably improved energetic and material efficiency as well as a lower space requirement. Higher perpass conversion in a single reactor can be achieved and almost 100 times higher volumetric space-time yield $\left(1600-1800 \mathrm{~kg} \mathrm{~m}^{-3} \mathrm{~h}^{-1}\right)$ compared to industrial FTS reactors $\left(20 \mathrm{~kg} \mathrm{~m}^{-3} \mathrm{~h}^{-1}\right)$ can be reached. Higher specific performances, increased safety and optimal process control also lead to significant cost reductions and resource efficiency. Together with compactness and modularity of these reactors, implementation of decentralized plants seems feasible in the framework of the energy transition. [5-13]

Another advantage of microstructured reactors is the possibility of a dynamic operation $[14,15]$. The response time of the reactor is tremendously shortened by its compactness with regard to temperature, concentration and feed flow. Thus, process parameters can be changed quickly in microstructured systems. This is extremely relevant, if an FTS plant would solely depend on volatile renewable energy, i.e. the produced hydrogen. The operating conditions of the reactor must be adaptable in short period to react to these fluctuations. The only alternative would be the provision of a correspondingly large, expensive buffer for hydrogen.

For economical and safe operation, knowledge about conversion and selectivity in the reactor as well as heat integration and material flows in the plant are required information. Dynamic process simulation is able to calculate species distribution, heat flows and product composition at any time at any location inside the plant. In the case of the complex Fischer-Tropsch product composition, the species distribution is hardly to assess experimentally; lots of effort is required to determine the product composition every minute[14,15] . One issue is a suitable kinetic model for chemical synthesis for the prediction, design and optimization of microstructured reactor behavior [5]. Furthermore, residence time distribution and correct description of the phase equilibria in the two-phase or sometimes even three-phase flow of the FT product (including water) at product condensation traps are required for description of plants.

This contribution is devoted to deliver the three major elements: kinetics, residence time distribution and the strategy for phase description - all experimentally verified from a pilot scale test rig. The strategy could be applied to larger FT plants to derive the mean composition of the product depending on the input, i.e. wind or solar energy and their respective location. From an economic point of view, it has already been verified in previous contributions that at constant $\mathrm{H}_{2} / \mathrm{CO}$ ratio a constant conversion manipulated by the reactor temperature could lead to rather constant product distribution over a real-time photovoltaics energy profile $[14,15]$. Heat flows are not yet considered but may be addressed in upcoming further publications.

\section{Material and methods}

\subsection{Experimental setup}

The core components of the plant are: mass flow controllers for gas feeding, an evaporation-cooled microstructured packed bed FT reactor, a hot trap (HT) and a micro heat exchanger $(\mu \mathrm{HE})$ for product condensation before a cold trap (CT); details see elsewhere [14,16]. The boiling point of the cooling water cycle is controlled by pressure regulation so that the desired reactor temperature can be adjusted in autothermal reactor operation; heat cartridges are used to preheat to ignition temperature of the reaction (approx. $190{ }^{\circ} \mathrm{C}$ ). The product leaving the reactor is mainly gaseous and is fed to the HT via a heated pipeline. In order to condense hydrocarbons which are solid at ambient conditions, the product stream is cooled to approx. $170{ }^{\circ} \mathrm{C}$ in the HT. This product fraction will be called "wax". The remaining gas flow leaves the HT and flows through the $\mu \mathrm{HE}$ into the CT. The gas is cooled to approx. $10{ }^{\circ} \mathrm{C}$ and the liquid products, which consist of an oil phase and a water phase, are condensed. The remaining gas from the CT is analyzed in a gas chromatograph (GC) for product analysis. If necessary, gas is directed to a mass spectrometer (MS) via a needle valve during sampling at a Quick Sampling site before the cold trap; details see elsewhere. [14-16]

\subsection{Experimental data for fitting kinetics}

Different experimental campaigns were conducted, analyzed and included into the reactor description via a microkinetic model. An overview of the used process parameters can be found in Table 1.

Experiments were executed on a commercial $20 \mathrm{wt}$ - $\%$ Co-alumina catalyst with $0.5 \mathrm{wt}-\%$ Re promotor. The catalyst has been aged by a multitude of experiments $[14,15]$ to provide a sound basis of parameter combinations with regard to catalyst activity and selectivity. The loaded particle diameter was 50-200 $\mu \mathrm{m}$. To guarantee negligible effect of catalyst deactivation, the operation was limited to the following conditions: temperature from 225 to $245.5^{\circ} \mathrm{C}$, a total pressure from 2.0 to $3.0 \mathrm{MPa}$, a weight hourly space velocity (WHSV) from 4.37 to $7.74 \mathrm{~h}^{-1}$, a nitrogen dilution from 1.89 to $20.00 \%$ and a syngas ratio from 1.48 to 2.20 . Since the overall results are influenced by the kind of catalyst and its state, i.e. the time on stream (TOS) and previous experiments, the obtained characteristics are only valid for this specific catalyst state. In order to increase model accuracy also for real plant operation, experiments including time dependency of catalyst activity would be required.

\subsection{Dead time experiments}

The dead time measurements performed with the MS are detailed in a previous work [14]. These measurements have been applied to fit the residence time model according to sections 2.4. $\mathrm{CO}_{2}$ was used as a tracer with 5 vol- $\%$ of the dosed gas content in non-reactive gas flow. It replaced 5 vol- $\%$ of $\mathrm{N}_{2}$ to keep the total gas flow. In Table 2, the experimental conditions are shown.

The required time to measure 5 vol- $\%$ of $\mathrm{CO}_{2}$ in the gas flow was defined as the total dead time after individual parts of the test rig. An overview of different volumes, applied temperature levels and determined dead times is shown in Table 3. The trap temperatures were chosen in order to obtain appropriate hydrocarbon cuts in each respective trap.

Discrepancy between measured dead times and hydrodynamic residence time $\tau_{\text {hyd }}$ of a component is result of back-mixing and other effects [16]. The dead time before the reactor, i.e. that of the analytics, accounts to $0.4 \mathrm{~min}$ and needs to be subtracted from all values. Since the distance between the HT and the $\mu \mathrm{HE}$ is considerably short, the resulting dead time after both components was very similar. 
Table 1

Experimental data and results for 20 steady-state experiments with the microstructured pilot scale reactor.

\begin{tabular}{|c|c|c|c|c|c|c|c|c|c|c|}
\hline Experiment \# & $\dot{\boldsymbol{V}}\left[\mathrm{L} \mathrm{min}^{-1}\right]$ & $\mathrm{H}_{2} / \mathrm{CO}$ ratio [-] & Dilution [\%] & $W H S V\left[\mathbf{g}_{\text {gas }} \mathbf{g}_{\text {cat }}^{-1} \mathbf{h}^{-1}\right]$ & $T\left[{ }^{\circ} \mathrm{C}\right]$ & $p_{\text {total }}[\mathrm{MPa}]$ & $X_{C O}[\%]$ & $X_{H 2}[\%]$ & $S_{C 1}[\%]$ & $S_{C 5+}[\%]$ \\
\hline 1 & 17.526 & 2.20 & 2.70 & 5.23 & 239.0 & 3.0 & 43.29 & 48.56 & 13.74 & 76.71 \\
\hline 2 & 15.528 & 1.96 & 3.04 & 4.91 & 238.0 & 3.0 & 40.53 & 48.75 & 12.98 & 77.77 \\
\hline 3 & 16.263 & 1.96 & 17.65 & 6.20 & 225.0 & 3.0 & 29.11 & 35.26 & 10.84 & 80.38 \\
\hline 4 & 14.309 & 1.49 & 20.00 & 6.08 & 235.0 & 3.0 & 42.06 & 63.94 & 9.82 & 81.86 \\
\hline 5 & 15.290 & 1.48 & 18.75 & 6.15 & 235.0 & 3.0 & 43.55 & 54.26 & 11.12 & 80.27 \\
\hline 6 & 17.249 & 2.19 & 16.67 & 6.27 & 235.5 & 3.0 & 50.24 & 56.85 & 13.21 & 77.11 \\
\hline 7 & 16.272 & 1.96 & 17.65 & 6.21 & 235.5 & 3.0 & 47.74 & 57.15 & 12.48 & 78.23 \\
\hline 8 & 16.360 & 1.96 & 17.65 & 6.24 & 235.5 & 2.5 & 43.98 & 53.01 & 13.41 & 76.71 \\
\hline 9 & 16.492 & 1.96 & 17.65 & 6.29 & 235.0 & 2.0 & 35.86 & 43.59 & 13.54 & 75.88 \\
\hline 10 & 14.304 & 1.49 & 20.00 & 6.08 & 245.0 & 3.0 & 46.28 & 71.70 & 20.03 & 64.16 \\
\hline 11 & 15.281 & 1.73 & 18.75 & 6.14 & 245.5 & 3.0 & 55.98 & 77.75 & 14.20 & 74.76 \\
\hline 12 & 17.273 & 2.18 & 16.67 & 6.28 & 245.0 & 3.0 & 75.40 & 79.26 & 16.03 & 74.20 \\
\hline 13 & 16.297 & 1.95 & 17.65 & 6.22 & 244.8 & 3.0 & 69.73 & 79.55 & 13.96 & 77.16 \\
\hline 14 & 16.360 & 1.96 & 17.65 & 6.24 & 245.0 & 2.5 & 58.52 & 68.96 & 14.87 & 75.08 \\
\hline 15 & 13.745 & 1.96 & 3.45 & 4.37 & 244.5 & 3.0 & 67.37 & 80.22 & 13.60 & 77.45 \\
\hline 16 & 14.692 & 2.18 & 3.23 & 4.42 & 241.5 & 3.0 & 63.49 & 68.12 & 14.56 & 76.36 \\
\hline 17 & 17.747 & 1.98 & 2.68 & 5.43 & 245.0 & 3.0 & 65.25 & 69.81 & 13.98 & 77.21 \\
\hline 18 & 22.913 & 2.11 & 2.10 & 6.96 & 244.5 & 3.0 & 49.05 & 58.83 & 14.60 & 74.90 \\
\hline 19 & 25.574 & 2.00 & 1.89 & 7.74 & 244.5 & 3.0 & 41.58 & 49.16 & 14.25 & 74.90 \\
\hline 20 & 17.788 & 1.98 & 2.68 & 5.45 & 235.5 & 3.0 & 36.06 & 43.47 & 13.30 & 76.55 \\
\hline
\end{tabular}

\subsection{Residence time distribution}

The description of the residence time distribution (RTD) is an important part for the simulation of a chemical plant [18]. It indicates the average residence time of a species in specific plant components.

$F(t)$ is the residence time sum function. It indicates the share of molecules that has left the reactor up to time t. It can be determined directly from a displacement marking experiment as described in section 2.3. The mean residence time $\tau_{\text {mean }}$ is the first moment $\mu_{1}$ of the residence time density function $E(t)$ :

$\tau_{\text {mean }} \equiv \mu_{1}=\int_{0}^{\infty} t E(t) d t=\int_{0}^{1} t d F(t)$

In order to compare the RTD for different applications, the dimensionless time variable $\theta$ can be introduced:

$\theta=t / \tau_{\text {hyd }}$

\subsubsection{Choice of residence time model for the FT reactor}

Model reactors are ideal reaction systems with clearly defined system properties [17]. The ideal plug flow reactor (PFR) model for gas phase applications may describe microstructured reactor systems quite well, even though laminar flow is the predominant regime. This is because radial diffusion is occurring fast over the small radius and evens out the residence time distribution imposed by the parabolic velocity profile.

\subsubsection{Tanks-in-series model}

In this work, all plant components are described with regard to the residence time distribution by the tanks-in-series (TIS) model. The TIS is based on a cascade of interconnected CSTRs with a volume $V_{n}$, which is the respective component volume $V_{\text {total }}$ divided by $N$, the number of CSTRs. With increasing number $N \rightarrow \infty$ the cascade approaches a PFR character. Non-ideal reactors can be described by a combination of several TIS models in parallel. For the TIS, the following equation is valid for a reactor component:
Table 3

List of volumes, applied temperatures and the total dead time after the main components of the test rig.

\begin{tabular}{llll}
\hline System component & $V[\mathrm{~L}]$ & $T\left[{ }^{\circ} \mathrm{C}\right]$ & Total dead time [min] \\
\hline Reactor & 0.15 & $220-250$ & 1.4 \\
HT $/ \mu \mathrm{HE}$ & 4.8 & 170 & 17.5 \\
$\mathrm{CT}$ & 25 & 10 & 82.2 \\
\hline
\end{tabular}

$\tau_{\text {hyd }}=V_{\text {total }} / \dot{V}=\frac{1}{\dot{V}} \sum_{n=1}^{N} V_{n}=C_{0} \sum_{n=1}^{N} \Delta X_{n} /-r_{n}$

with $V_{\text {total }}$ : Total component volume $\left[\mathrm{m}^{3}\right]$,

$N$ : Total number of CSTR in series [-],

$n$ : Number of CSTR in series [-],

$V_{n}$ : Volume of one CSTR $\left[\mathrm{m}^{3}\right]$,

$C_{0}$ : Input concentration $\left[\mathrm{mol} \mathrm{m}^{-3}\right]$,

$\Delta X_{n}$ : Conversion difference obtained in CSTR number $n[-]$,

$r_{n}$ : Reaction rate in CSTR number $\mathrm{n}\left[\mathrm{mol} \mathrm{m}^{-3} \mathrm{~s}^{-1}\right]$.

In non-reactive flow, the residence time sum function can be expressed via the number of CSTRs as follows:

$F(\theta)=1-\exp (-N \theta) *\left[1+N \theta+\frac{(N \theta)^{2}}{2 !}+\cdots+\frac{(N \theta)^{N-1}}{(N-1) !}+\cdots\right]$

With this equation the $\mathrm{CO}_{2}$ tracer experiments described in section 2.3 can be fitted by varying $N$.

\subsubsection{RTD modelling and determination of the CSTR number $N$ for all test} rig components

As described in section 2.4 .2 the experimentally determined $F$ curves of each individual component were fitted to equation (5). Fig. 1 shows the $F$-curves determined from $\mathrm{CO}_{2}$ tracer experiments, as well as their description with the TIS models and the corresponding CSTR numbers for the different system components.

Two TIS models fit the experimentally determined $\mathrm{CO}_{2}$ response of the reactor because of the observed step. The first section of the plot is

Table 2

Experimental conditions during dead time determination in non-reactive flow [14].

\begin{tabular}{|c|c|c|c|c|c|c|c|}
\hline Setup & $\dot{V}\left[\mathrm{~L} \mathrm{~min}^{-1}\right]$ & $\mathrm{H}_{2}$ content [vol.- $\left.\%\right]$ & $\mathrm{N}_{2}$ content [vol.-\%] & CO content [vol.-\%] & $\mathrm{CO}_{2}$ content [vol.- $\left.\%\right]$ & $T\left[{ }^{\circ} \mathrm{C}\right]$ & $p_{\text {total }}[\mathrm{MPa}]$ \\
\hline $\mathrm{CO}_{2}$ on/off & 20 & 95 & $5 / 0$ & 0 & $0 / 5$ & 225 & 3 \\
\hline
\end{tabular}




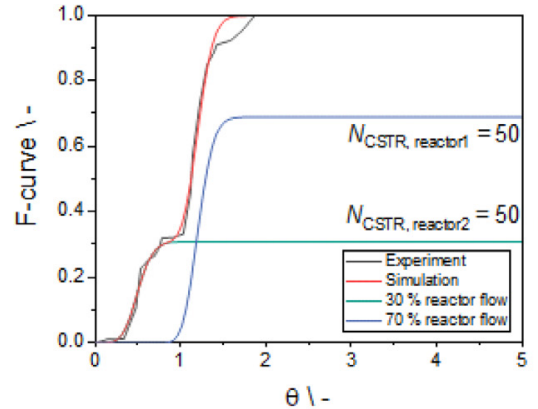

(a)

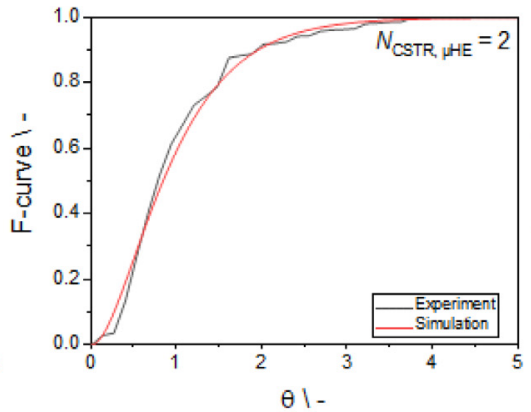

(b)

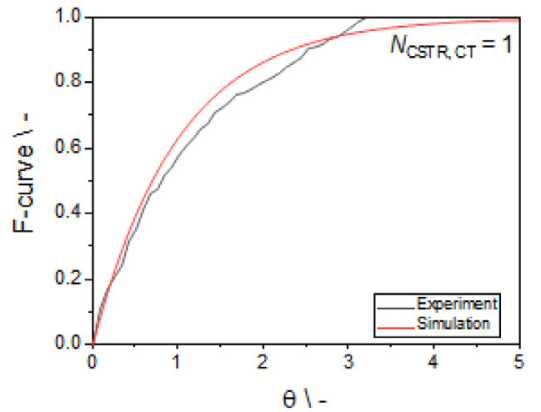

(c)

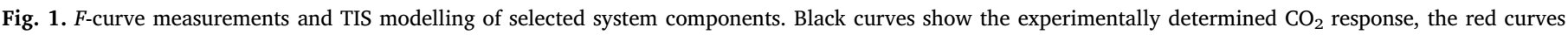

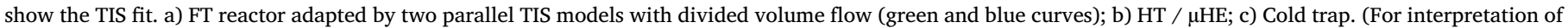
the references to colour in this figure legend, the reader is referred to the web version of this article.)

described by is a cascade of 50 CSTRs for $30 \%$ of the volume flow. The second section is adapted with a cascade of 50 CSTRs for $70 \%$ of the volume flow. A CSTR number of 50 corresponds to a Bodenstein number of 100 , which is equivalent to a PFR behavior. Reasons for the observed step could originate from either inhomogeneously packed microstructures and/or back-mixing in the connecting flanges.

The HT could be described by a series connection of two CSTRs, while the CT behaves almost like an ideal CSTR as shown in Fig. 1c.

\subsection{Reaction kinetics}

The reaction mechanism of the FTS is a debate in literature. There is no simplified mechanism that can predict the entire product spectrum [18]. Therefore, it is typically assumed that different reaction routes exist during the reaction, which run in parallel and thus lead to complex product distribution. The FTS is reported to begin with the formation of a $\mathrm{CH}_{2}$ monomer, which grows to longer hydrocarbon chains via a polymerization reaction [19].

The elementary steps of the FTS can be summarized as follows:

1. adsorption and eventually dissociation of $\mathrm{H}_{2}$ and $\mathrm{CO}$,

2. chain initiation by formation of the $\mathrm{CH}_{2}$ monomer at the surface,

3. chain growth by addition of C-species,

4. chain termination by full hydrogenation of a terminal $\mathrm{C}$-atom or dehydrogenation of a $\mathrm{C}-\mathrm{C}$ bond,

5 . desorption of the products.

In detail, literature distinguishes between the carbide, alkyl, CO insertion and enol mechanism [19-27]. In macrokinetic approaches, products are grouped together for simplicity (lumping of species). This is only applicable if the rate-determining step is the formation of monomers and the resulting products do not influence monomer formation [19].

Without discussion and detailed assessment on the real mechanism, we decided to use an adapted microkinetic model based on the alkyl mechanism, developed by Kwack et al. [19], which was able to describe the reactor behavior with good preciseness. This model was also appropriate to describe data from microstructured FT lab reactors in similar circumstance $[18,28]$.

\subsection{Reactor modelling}

Appropriate assumptions must be made for a realistic description of the reactor. Based on the criteria of Mears and Weisz-Prater [29-31], various boundary conditions and reaction conditions were examined and found to fulfill the absence of mass transport limitation. Transport limitations through the liquid film in and around single particles was also considered to be absent; this is proven in earlier work [28] and supported by modelling done for small catalyst particles [32] as applied in our work. Thus, a pseudo-homogeneous stationary reactor model was chosen. Since a Bodenstein number of 100 was determined from the acquired residence time distribution, ideal plug flow (PFR) was set for the description of conversion and selectivity in the packed microstructures. A step-wise stationary description in this circumstance seems also valid because the mean residence time in the reactor is negligible compared to the rest of the test rig and because reaction follows condition changes immediately $[14,15]$. The reactor is described isothermal (see also $[8,16]$ ) and isobaric. Pressure losses over the catalyst bed was determined to be negligible with $\Delta p_{\text {total }}$ less than 0.5 bar at 30 bar, i.e. less than $2 \%$ change.

Fig. 2 shows the principle of the PFR description as applied in the software Matlab ${ }^{\circledR}$.

A cell model discretizing the reactor was used. Temperature, pressure and volume flow of the reactants are input variables. The mass balance equations are solved for each individual cell in a loop, in which the material properties are continuously updated and applied as input for the calculation of the next cell. For a small volume element ( $S d z$ ) the PFR equation is written as follows:

$\frac{d m_{i}}{d t}=\left(\dot{m} w_{i}\right)_{z}-\left(\dot{m} w_{i}\right)_{z+d z}+M_{i} r_{i} S d z$

With the assumption of $\dot{m}_{0}=\dot{m}_{L}=\dot{m}=\operatorname{constant}$ (stationary) it can be written as

$\frac{d m_{i}}{d t}=0 \rightarrow\left(\dot{m} w_{i}\right)_{z}-\left(\dot{m} w_{i}\right)_{z+d z}=-M_{i} r_{i} S d z$ gives

Replacing $\left(w_{i}=M_{i} C_{i} / \rho\right),(\dot{m}=\dot{V} \rho),\left(\dot{V} C_{i}=\dot{N}_{i}\right)$ and $(S d z=d V)$

$\left(\dot{N}_{i}\right)_{z}-\left(\dot{N}_{i}\right)_{z+d z}=-r_{i} d V$

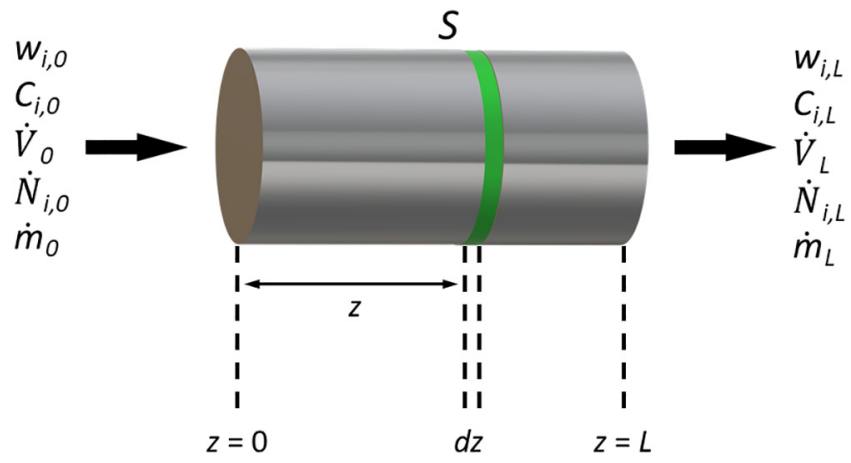

Fig. 2. Schematic of the PFR model for description of the microstructured interior reaction process. 


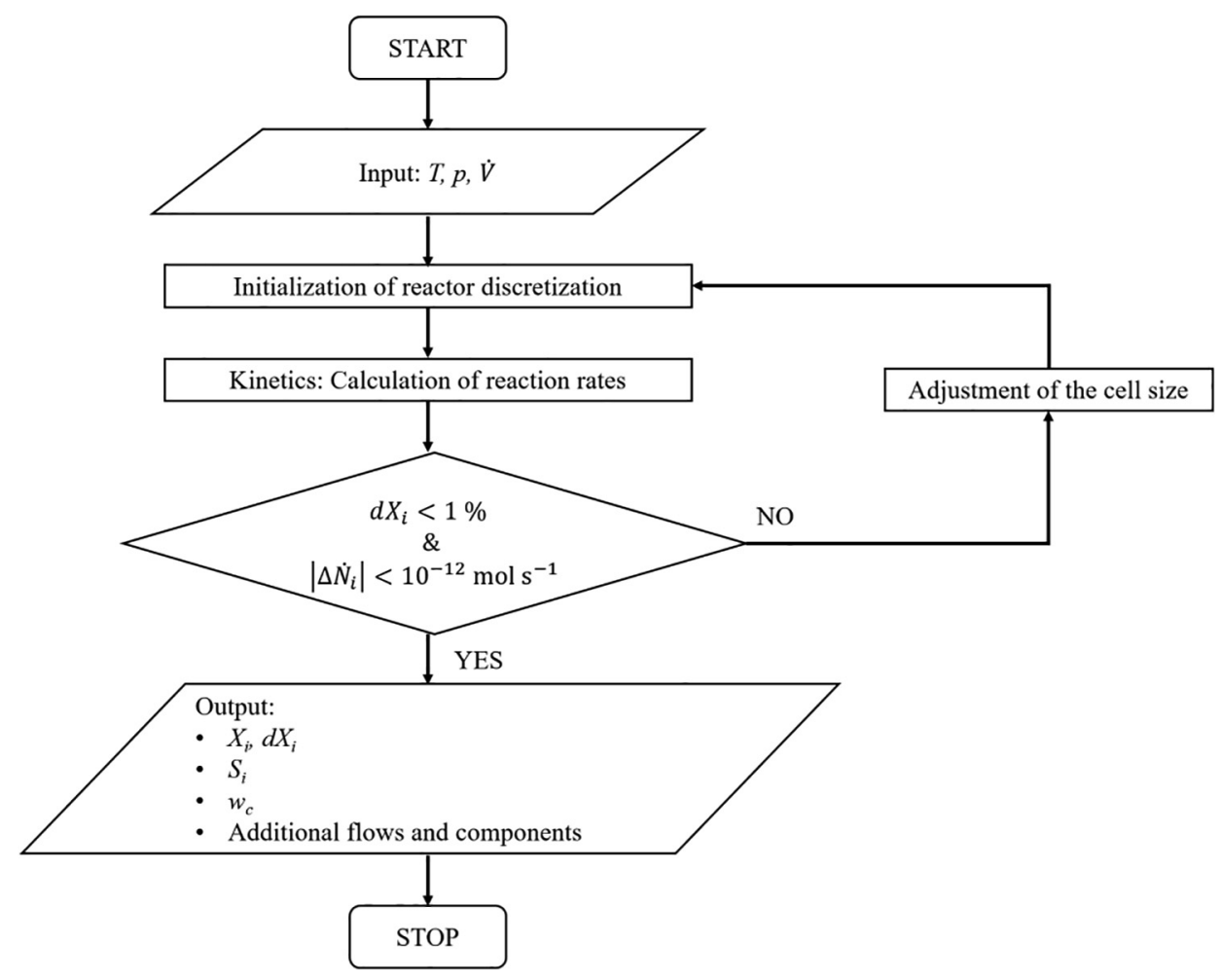

Fig. 3. Flowchart for discretizing the reactor during calculation of conversion and selectivity.

In differential notation this is

$-d \dot{N}_{i}=-r_{i} d V$

Finally, the molar change of the species $i$ in a cell is

$d \dot{N}_{i, \text { cell }}=d V_{\text {cat }} \cdot r_{i, \text { cell }}(z+d z)$

To be grid-independent, the cell size was reduced in the iteration until the conversion change in each step was less than $1 \%$ and the difference between the mole flows for $\mathrm{H}_{2}$ and $\mathrm{CO}$ of the input and output of a cell were less than $10^{-12} \mathrm{~mol} \mathrm{~s}^{-1}$. Fig. 3 visualizes the algorithm as a flowchart.

\subsection{Vapor-liquid equilibrium (VLE) description of the product condensation}

VLE modelling of Fischer-Tropsch product is a challenging topic due to the broad variety of components including polar, nonpolar, supercritical and subcritical components. Here, we propose the use of the group contribution-based volume-translated Peng-Robinson equation of state VTPR-GCEOS. It was developed for asymmetric multicomponent mixtures containing polar and nonpolar components and should thus yield reliable results for VLE calculations of Fischer-Tropsch related processes [33-35]. The use of an equation of state has the great advantage that the whole product spectrum can be described consistently with one equation.

The basic equation is a volume-translated form of the PengRobinson EOS (eq. 13) where the temperature dependent interaction parameters are based on group interaction parameters as in modified UNIFAC. For the $\alpha$ function the exponential approach developed by Twu et al. [36] is used. The concept of volume translation was neglected in this work since it was of no interest to calculate liquid densities. The volume translation parameter $c$ does not affect equilibrium calculations [37].

$p=\frac{R T}{v+c-b}-\frac{a(T)}{(v+c)(v+c+b)+b(v+c-b)}$
The calculation routines in MATLAB were adapted and validated from published example MATHCAD sheets [36]. Pure component property data (critical temperature, critical pressure and Twu $\alpha$ parameter) was taken from Twu et al. [36] and Bell et al. [38]. For longchain hydrocarbons (more than 20 carbon atoms) the critical data was estimated using group contribution methods $[36,39]$ and Twu $\alpha$ parameters were fitted to a vapor pressure correlation of Marano and Holder [40]. The acentric factor was calculated from Twu $\alpha$ parameters to guarantee internal consistency.

In the HT, a liquid and a gaseous phase are formed. Thus, a twophase flash based on the Rashford-Rice flash equation [40] was implemented. For the CT, a three-phase flash calculation based on a generalized Rashford-Rice equation was used to account for the immiscible oil and water phases. In each calculation all hydrocarbons were assumed to be n-alkanes.

\subsection{Model application in MATLAB ${ }^{\circledast}$}

Differential equations were solved with the ode45 solver. The optimization algorithm lsqnonlin, suitable for nonlinear problems was used to create a fit for experimental data. The sobolset function was used to determine the initial values during parameter optimization.

Reaction kinetics and the RTD model interact with each other and deliver coupled results for modelling of the FTS plant. Time-dependent product concentrations and properties such as conversion, selectivity, mass distribution and product formation in different fractions are predicted. Fig. 4 gives a schematic of the modelling approach.

Based on the developed RTD model, mixing and flow properties can be predicted. To calculate flow mixing, two different operating conditions can be used as an input. A mixing ratio of both sets of conditions can be given between 0 and 1 , from which a product distribution will be calculated. Alternatively, a mixing time for both sets of conditions can be specified, from which the product distribution will be calculated.

For each separator and for each method of mixing, a $p-T$ flash is performed to calculate the VLE. An input stream is immediately separated into a liquid and a vaporous product. 


\section{OUTPUT}

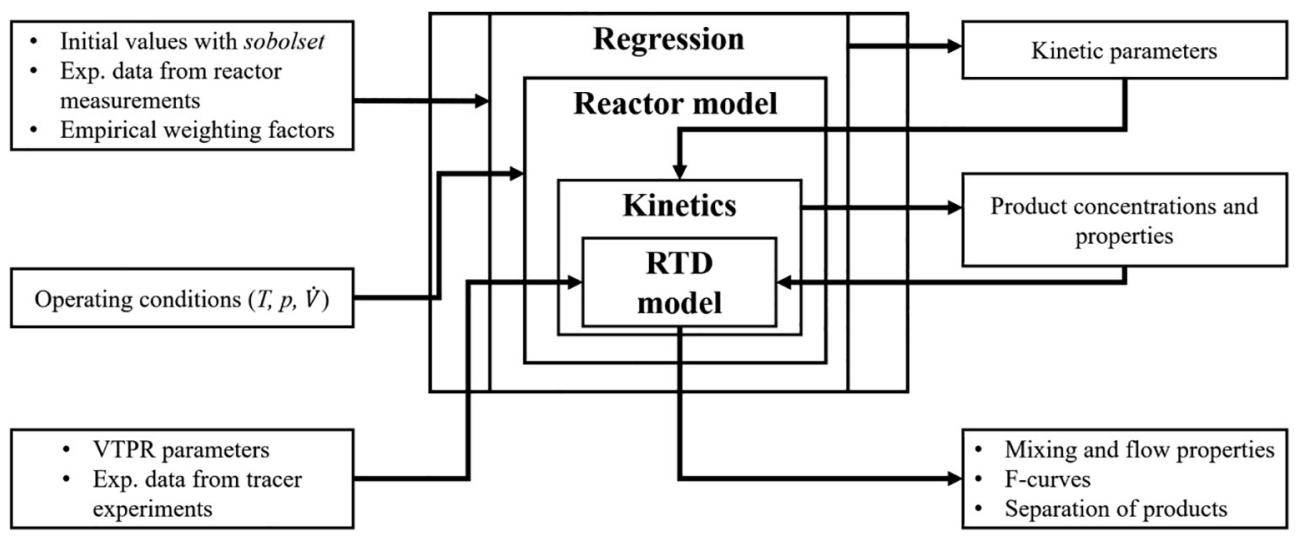

Fig. 4. Overview of the modelling approach.

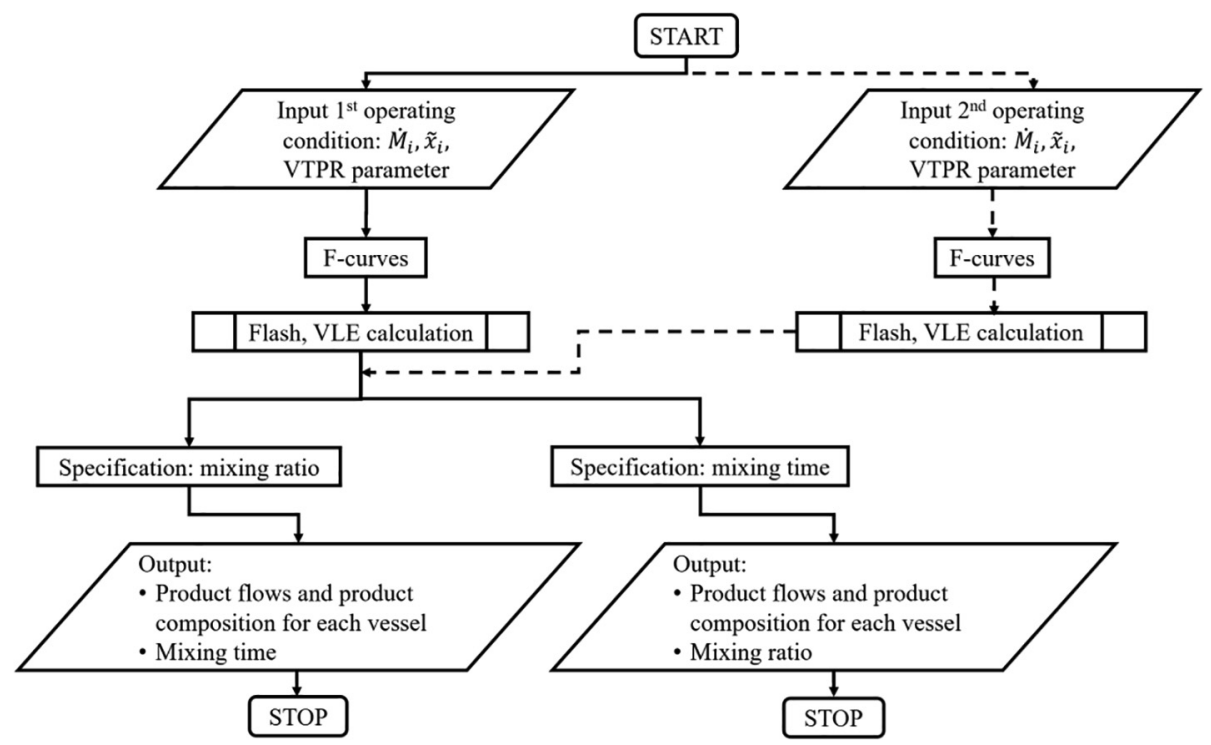

Fig. 5. Program flowchart for the calculation of mixing states.

If a process parameter changes, product quality is also shifting. Mixing of two fluids was thus implemented in the routine. Fig. 5 shows a schematic representation of the calculation of the mixing states. Flow properties and product concentrations are calculated separately for different operating conditions using the VLE. If the mixing ratio is specified, a $\theta$-value is determined based on the $F$-curve of the respective system component. Since the volume and flow rate of the system components are known, an average residence time and thus the elapsed mixing time can be determined to calculate the concentrations in the mixed flow. If the mixing time is specified, a $\theta$-value is determined using equation (4). This allows determination of the $F$-value of the respective component. This $F$-value then corresponds to the mixing ratio with which the two flows of each operating conditions are mixed.

The gaseous phase can be described in each component via the determined F-curves (section 2.4.3). For the liquid phase this cannot be assumed. However, if the liquid is formed almost immediately when entering a specific component, the F-curve of the gaseous phase of the preceding component can be applied. Fig. 6 illustrates this approach.

Since both separators are not continuously discharged but manually emptied in time intervals, the available volume of the separators differs slightly for the gas phase over time. The effect of filling level of liquid was nevertheless neglected as influence on the RTD of the gas phase due to maximum liquid levels below $20 \%$.

\section{Model validation}

\subsection{Validation of the kinetic model}

To validate the kinetics and the reactor model, simulated mass distributions, conversions and each selectivity were compared with experimental data. Table 4 shows the results of the nonlinear regression for the determination of the kinetic parameters, as well as provided values from literature along with the model $[18,19]$. Two adsorption constants are determined $\left(K_{H_{2}}^{a d}\right.$ and $\left.k_{C O} K_{C O}^{a d}\right)$ for the reactants. In addition, five velocity coefficients $\left(k_{I N}, k_{G}, k_{C_{4}}, k_{2}, k_{i}\right)$ were adjusted, describing phenomena such as chain initiation, growth and termination, as well as the formation of methane and ethane. Two activation energies $\left(E_{I N}, E_{G}\right)$ were adjusted for chain start and chain growth.

Almost all kinetic parameters are in the same order of magnitude as the literature values. Deviations from literature are due to different operating conditions and catalysts, e.g. Kwack et al. performed their experiments at 20 bar, a temperature of $230{ }^{\circ} \mathrm{C}$ and a $\mathrm{H}_{2} / \mathrm{CO}$ ratio of 2 [19]. Good agreement is generally obtained with previous work from Sun et al. [18] where a much smaller microreactor has been applied but with oil cooling and not with evaporation cooling as in our case.

Fig. 7 shows the parity plots of selectivity for $\mathrm{C}_{1}$ and $\mathrm{C}_{5}$ - product phases - experiment versus simulation - for all operating conditions of 


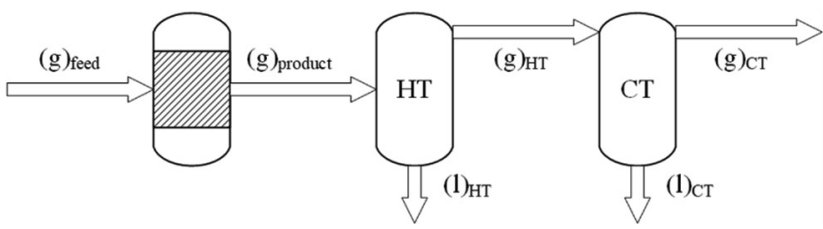

$(\mathrm{g})_{\text {feed }}:$ F-curve reactor

HT<smiles>CC=C[As]C</smiles>

CT

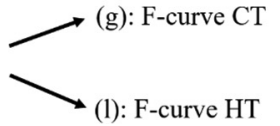

Fig. 6. Approach of applied F-curves for gas and liquid. "(g)" stands for the gaseous phase, "(l)" for the liquid phase.

Table 4

Adjusted kinetic parameters for the developed reaction model by Kwack et al. [19] - comparison of own values with literature values.

\begin{tabular}{|c|c|c|c|c|}
\hline Mechanism & Parameter & Unit & $\begin{array}{l}\text { Determined } \\
\text { value }\end{array}$ & $\begin{array}{l}\text { Literature } \\
\text { value }\end{array}$ \\
\hline & $K_{H_{2}}^{a d}$ & $\mathrm{bar}^{-1}$ & $2,98 \cdot 10^{-5}$ & "b $3,91 \cdot 10^{-5}$ \\
\hline & $k_{C O} \cdot K_{C O}^{a d}$ & $\mathrm{~mol} \cdot \mathrm{kg}^{-1} \cdot \mathrm{s}^{-1} \cdot \mathrm{bar}^{-1}$ & $2,15 \cdot 10^{-2}$ & ${ }^{* \mathrm{~b}} 5,82 \cdot 10^{-2}$ \\
\hline & ${ }^{*} k_{I N}^{0}$ & $\mathrm{~mol} \cdot \mathrm{kg}^{-1} \cdot \mathrm{s}^{-1}$ & $1,03 \cdot 10^{\circ}$ & "b $3,73 \cdot 10^{-1}$ \\
\hline & ${ }^{*} k_{G}^{0}$ & $\mathrm{~mol} \cdot \mathrm{kg}^{-1} \cdot \mathrm{s}^{-1}$ & $6,64 \cdot 10^{-1}$ & "b $4,33 \cdot 10^{-1}$ \\
\hline & $k_{\mathrm{CH}_{4}}$ & $\mathrm{~mol} \cdot \mathrm{kg}^{-1} \cdot \mathrm{s}^{-1}$ & $5,35 \cdot 10^{1}$ & "b $1,89 \cdot 10^{1}$ \\
\hline & $k_{2}$ & $\mathrm{~mol} \cdot \mathrm{kg}^{-1} \cdot \mathrm{s}^{-1}$ & $2,56 \cdot 10^{\circ}$ & ${ }^{* \mathrm{~b}} 1,46 \cdot 10^{\circ}$ \\
\hline & $\boldsymbol{k}_{i}$ & $\mathrm{~mol} \cdot \mathrm{kg}^{-1} \cdot \mathrm{s}^{-1}$ & $5,47 \cdot 10^{\circ}$ & "b $1,21 \cdot 10^{1}$ \\
\hline & $E_{I N}$ & $\mathrm{~J} \cdot \mathrm{mol}^{-1}$ & $1,28 \cdot 10^{5}$ & ${ }^{*}{ }^{\circ} 7,99 \cdot 10^{4}$ \\
\hline & $E_{G}$ & $\mathrm{~J} \cdot \mathrm{mol}^{-1}$ & $8,87 \cdot 10^{4}$ & ${ }^{* b} 9,95 \cdot 10^{4}$ \\
\hline
\end{tabular}

*a $k=k^{o} \cdot \exp \left(-E_{a} / R^{*}\left(1 / T-1 / T_{\text {ref. }}\right)\right), T_{\text {ref. }}=513.15 \mathrm{~K}$,

*b value from Kwack et al. [19].

*c value from Sun et al. [18].

Table 1. It can be seen that the selectivity to the chosen fraction in the simulation are in good agreement with experimental data.

It must be noted that the selectivity to the $\mathrm{C}_{5+}$ fraction is an integral value. Therefore, differences between simulation data and experiments are less apparent than when comparing the selectivity of a single species such as methane. A maximum deviation of $10 \%$ for most results is obtained.

Fig. 8 shows the simulation and experimental mass distributions at two exemplary operating conditions. Inaccurate representations of the mass distribution in the $\mathrm{C}_{3}-\mathrm{C}_{8}$ range has mainly the reason that two GC data sets are summed up - the gas and liquid phase analysis; in combination, nitrogen as internal standard and the total amount of formed liquid are used to offset the two measurements.

In addition, the model only considers hydrocarbons up to a chain length of 50. Iso-alkanes and alkenes are also not considered in the simulation. These simplifications were done because the mass fraction

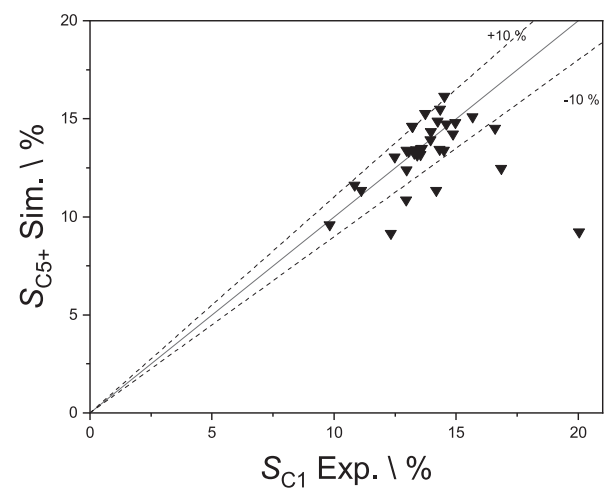

of the $\mathrm{C}_{50+}$ fractions is on average less than two percent and thus negligible. The mass fraction of alkenes and iso-alkanes is between five and ten percent each, so that this may be an additional source of error if these molecules behave as intermediates and not as unreactive products [41].

Fig. 9 shows the comparison of experiment and simulation with regard to $\mathrm{CO}$ and $\mathrm{H}_{2}$ conversion.

Fig. 9 a) and b) show that conversion increases with higher temperature in simulation and experiments, which corresponds to known kinetic effects. Between 230 and $240{ }^{\circ} \mathrm{C}$ the model shows its highest validity. In Fig. 9 c) and d) opposite trends of simulation and experiment can be observed. At a fixed WHSV, the CO partial pressure determines possible product flow. Thus, for increasing $\mathrm{H}_{2} / \mathrm{CO}$ ratio (without nitrogen balance) the total volume flow must be adjusted. By this approach, the residence time in the reactor decreases. Accordingly, the conversion could also decrease. As a contradicting effect, an increased $\mathrm{H}_{2} / \mathrm{CO}$ ratio results in a higher partial pressure of $\mathrm{H}_{2}$, which could increase conversion. Experimental results show that the effect of the increased hydrogen partial pressure predominates. In the simulation, however, the residence time decrease seems to dominate. Fig. 9 e) and $\mathrm{f}$ ) illustrate the effect of a decreasing residence time at constant $\mathrm{H}_{2}$ / $\mathrm{CO}$ ratio. Conversion decreases with lower residence time for simulation and experiment. Parity plots (not shown) exhibit a satisfactory representation of the conversion within $10 \%$ for $70 \%$ of all data sets.

Apart from the reported deviations in the $\mathrm{C}_{3}-\mathrm{C}_{8}$ range due to potential experimental error, other sources of error could occur from the homogeneous, ideal PFR description although from RTD experiments two CSTR cascades with $N=50$ were required to describe the residence time distribution. Further work should be paid on the applied microkinetics, which seem to influence the opposite trends observed in Fig. 9 c) and d).

\subsection{Validation of model coupling}

To validate the coupling of the individual subroutines for reactor

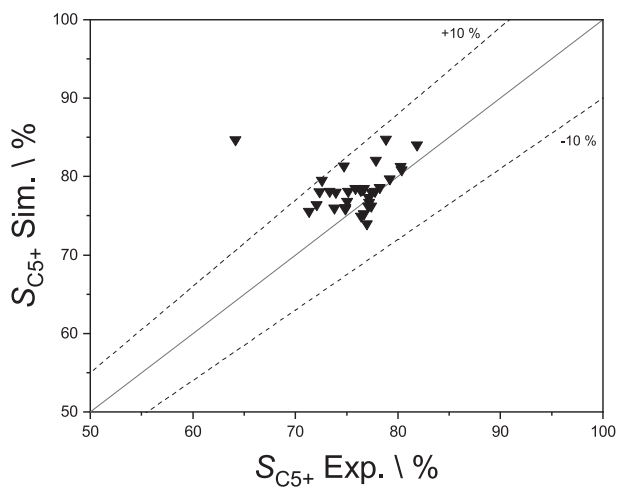

Fig. 7. Parity plots for simulated selectivity over experimentally determined selectivity from all experimental data provided in Table 1; (a) selectivity to methane; (b) selectivity to liquid products $\left(\mathrm{C}_{5+}\right)$. 

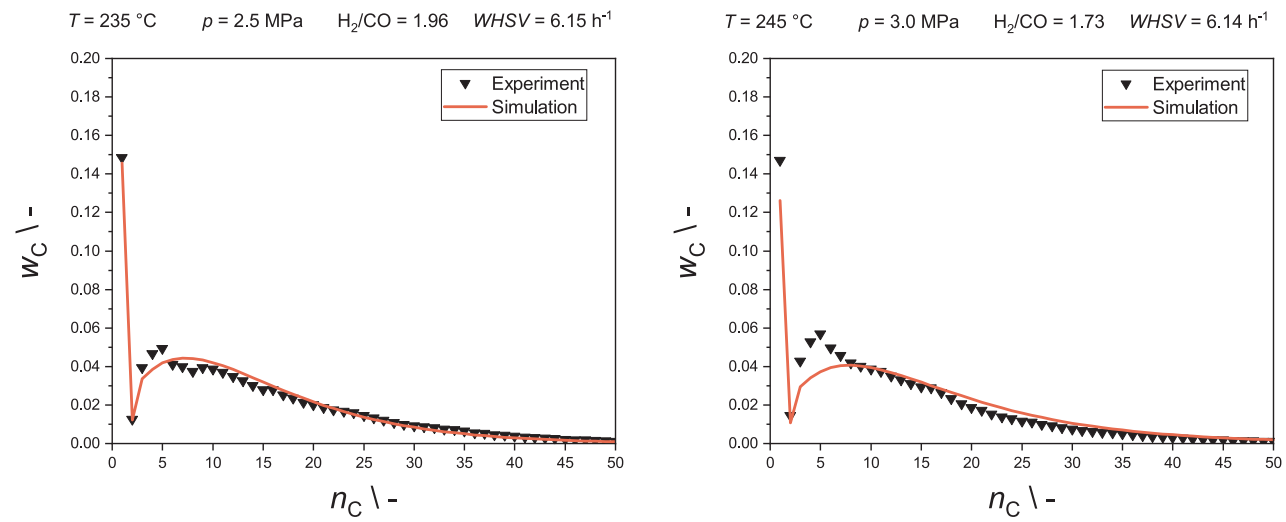

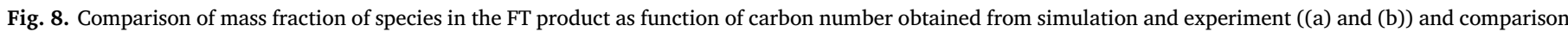
of Anderson-Schulz-Flory plots of simulation and experiment ((c) and (d)). Both setpoints were chosen for model validation and are thus not listed in Table 1.

description and flash calculation, steady-state experimental data of the individual analysis of gas, liquid and wax phase was compared to simulation with ideal [28] and EOS model. Feed for the flash calculation was generated by the reactor description subroutine. Fig. 10 a-c) show the comparison of the individual mass flow distribution of liquid in the HT and CT and of the residual gas phase, respectively.

The experimental mass distribution of the oil in the CT and the wax in the HT is in good agreement with the EOS model. Slight deviations can originate from the determination of the actual temperature inside the HT; only one temperature sensor is located at the outer wall and there might be a local temperature gradient inside. For the CT, slight deviations may occur in the measurement due to volatility of components from $\mathrm{C}_{4}$ to $\mathrm{C}_{8}$ when emptying the trap; liquids are stored at operating pressure and are drained versus ambient conditions in a sample container. The carbon mass balance, however, always resulted in $95-$ $97 \%$ of the initial carbon flow. The deviation between EOS simulation data and experiments is highest in in the gas phase since the formation of short hydrocarbons is underestimated by the kinetic subroutine. Nevertheless, the EOS model is superior over the calculation of mass flow distribution via the VLE with ideal assumptions, which differs significantly from the experimental data.

Coupling of kinetics, RTD and flash calculation is tested to describe load changes i.e. dynamic operation of an FT-unit in the following. Fig. 11 a-c) show the calculated individual mass flow distribution as function of the mixing ratio $a$ between two different reaction conditions for liquid in the HT and CT and for the residual gas phase, respectively. The mixing ratio $a$ is a value between 0 and $1 . a=1$ equals $100 \%$ of the operating conditions at setpoint A. $a=0$ means $100 \%$ of the second operating conditions, i.e. at setpoint B. For intermediate values of $a$, the flows obtained from the two operating conditions are multiplied by this mixing ratio. This approach has no physical meaning but tests if the routines are working correct and that the mass flow distributions change accordingly for a transition between two different operating conditions.

Physical meaning is reached, when the mixing time is calculated from the actual volume flow through the test rig. The mixing time indicates how much time elapses for gas mixing of the respective component after the gas composition at the reactor inlet and thus at the reactor outlet changes. Still, the model assumes instantaneous liquid phase formation upon component entry.

For the gas phase in the HT, mixing times between 60 and $150 \mathrm{~s}$ for $a=0.3$ and mixing times between 400 and $800 \mathrm{~s}$ for $a=0.7$ are calculated depending on the overall flow rate. Thus, it can be concluded that the HT needs at least $800 \mathrm{~s}$ to reach a near steady-state gas composition after changing the reaction conditions. From results in section 2.4.3, the mean RTD of the gas phase in the HT is about $1000 \mathrm{~s}$. Thus, the calculation of the mass flow distribution with the overall model provides realistic results. Mixing times of 10 to $30 \mathrm{~s}$ are calculated for the liquid phase in the HT, since a change in operating conditions quickly affects the reactor and results in a fast change of the concentration in the liquid phase of the HT (see section 2.8).

For the gas phase in the CT, mixing times between 1000 and $2000 \mathrm{~s}$ for $a=0.3$ and mixing times between 4000 and $6000 \mathrm{~s}$ for $a=0.7$ are calculated depending on the overall flow rate. Thus, the CT needs at least $6000 \mathrm{~s}$ to establish a steady-state gas composition after changing operating conditions for the reactor. According to results from section 2.4.3, the mean RTD of the gas phase in the CT is approximately $5000 \mathrm{~s}$. Mixing times of 400 to $800 \mathrm{~s}$ were determined for the liquid phase. The product mixture must pass the HT and $\mu \mathrm{HE}$ until condensation can take place in the CT, which is again in line with the mean RTD of the HT.

Fig. 12 a-c) show the calculation of the individual mass flow distributions as function of the mixing time between two different reaction conditions for liquid in the HT and CT and for the residual gas phase, respectively. The graphs demonstrate the above-mentioned observations. With this data the product composition over time can be calculated for the different traps and integrated to give an overall indication of the product quality during frequent draining of the products in a plant, which is operated in dynamic mode. In the future, the actual calculated product composition can further be used to predict the optimum process conditions in each load state and to actively change reactor temperature to reach optimum product composition. Other possibilities of control mechanisms are laid down in our previous work [15].

\section{Conclusions}

Within this work, a reactor model for a pilot scale microstructured fixed-bed reactor was adapted and approved to cover the main tendencies in the experimentally observed Fischer-Tropsch product composition.

Reaction kinetics were fitted with MATLAB ${ }^{\circledR}$. With the help of a nonlinear regression, rate and activation coefficients were in good agreement with previous work in smaller reactors highlighting the safe scale-up even at changing the heat removal from oil cooling to evaporation cooling. The reaction kinetics subroutine provided a satisfactory representation of experimental results. There is still potential for improvement, especially in the prediction of $\mathrm{H}_{2}$ and $\mathrm{CO}$ conversion. The kinetic model could also be extended by implementing the formation of alkenes and iso-alkanes to describe processes, such as alkene re-adsorption. This would allow also describing their content in the overall model for better predicting the output of the pilot-scale setup.

A residence time model for the pilot-scale test rig was developed from non-reactive residence time experiments. A model based on the total residence time function ( $F$-curve) for each system component was 


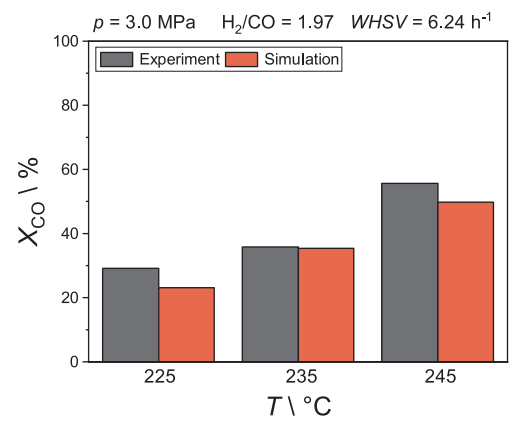

(a)

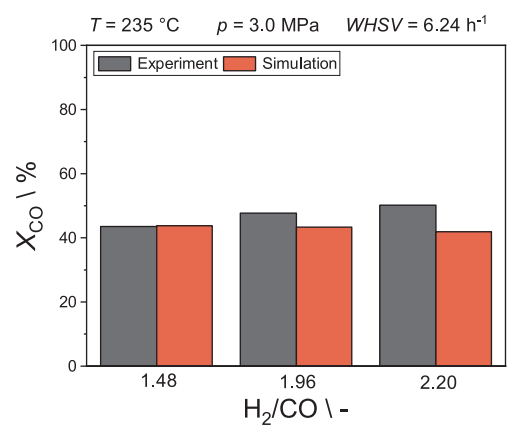

(c)

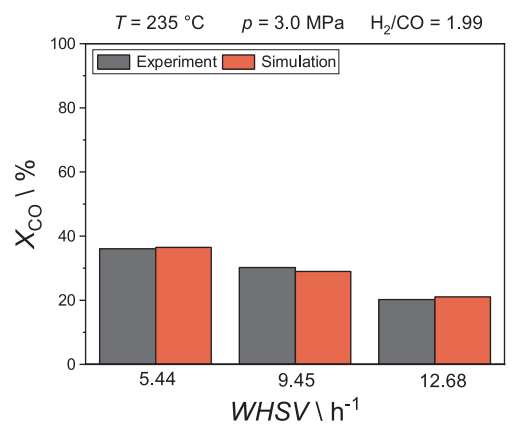

(e)

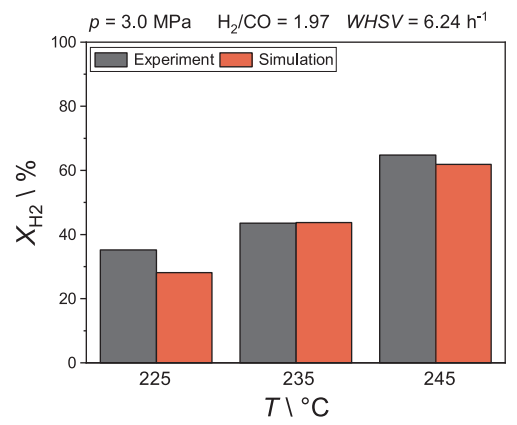

(b)

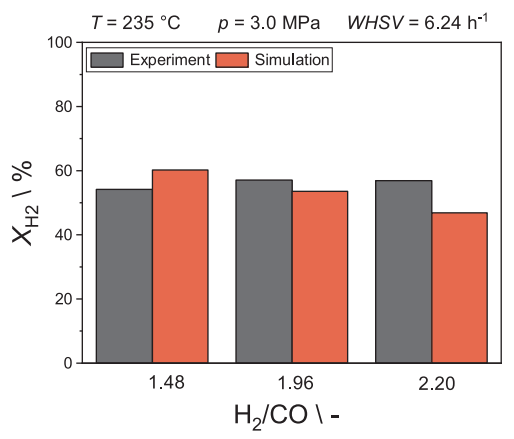

(d)

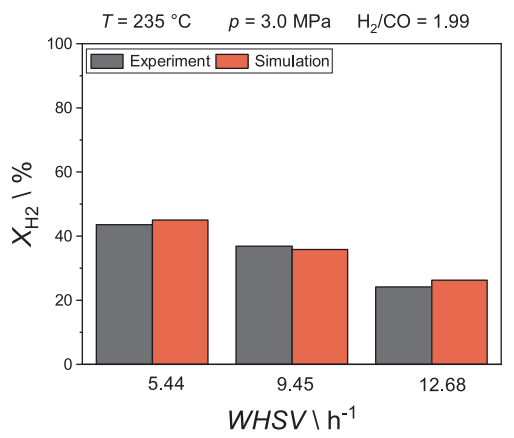

(f)

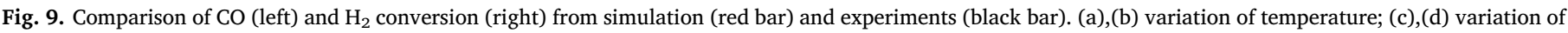

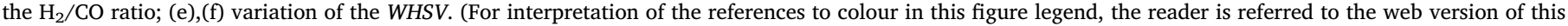
article.)
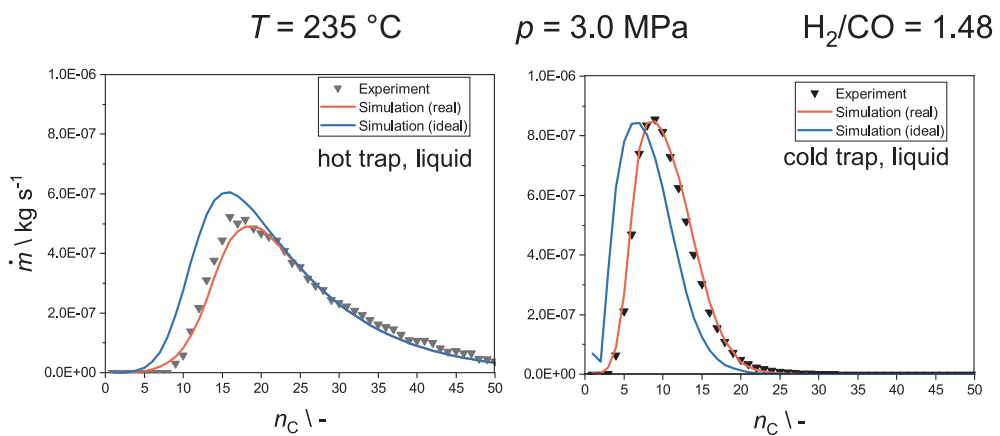

$W H S V=6.15$

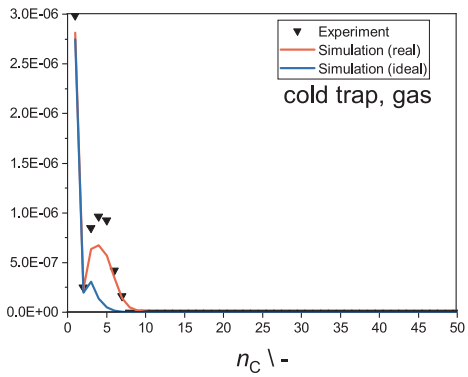

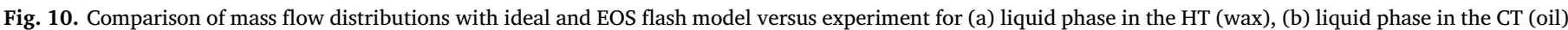

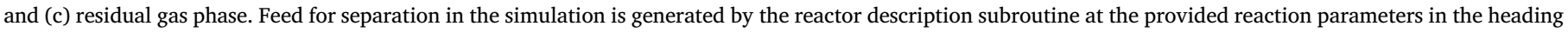
of the figure. 

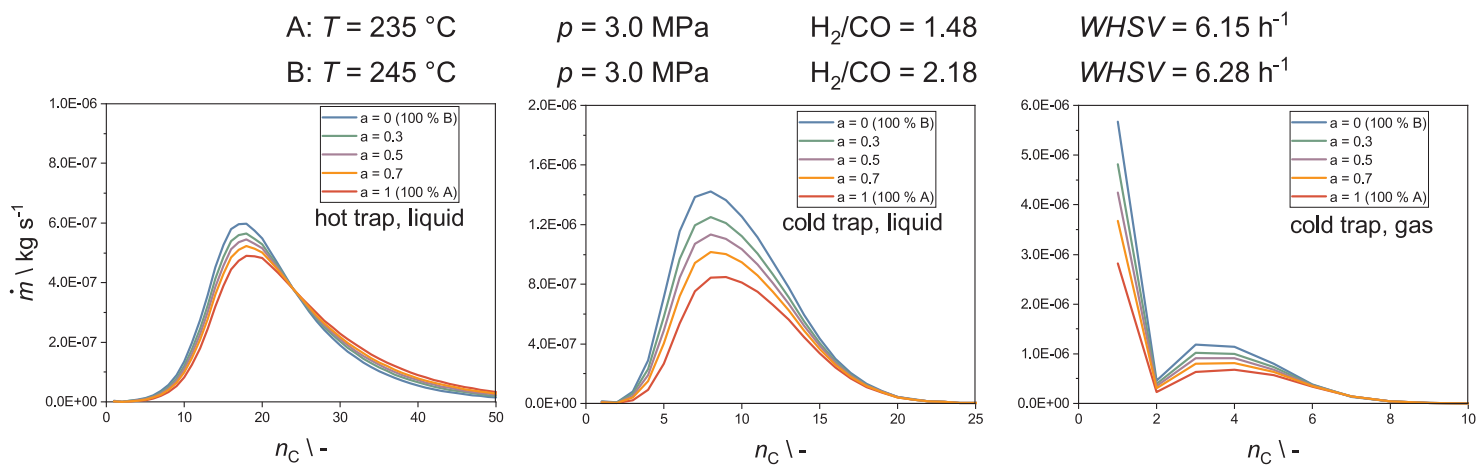

Fig. 11. Mass flow distributions according to the EOS flash model for (a) liquid phase in the HT (wax), (b) liquid phase in the CT (oil) and (c) residual gas phase for reaction conditions A and B and transitions between both conditions applying the mixing ratio $a$.
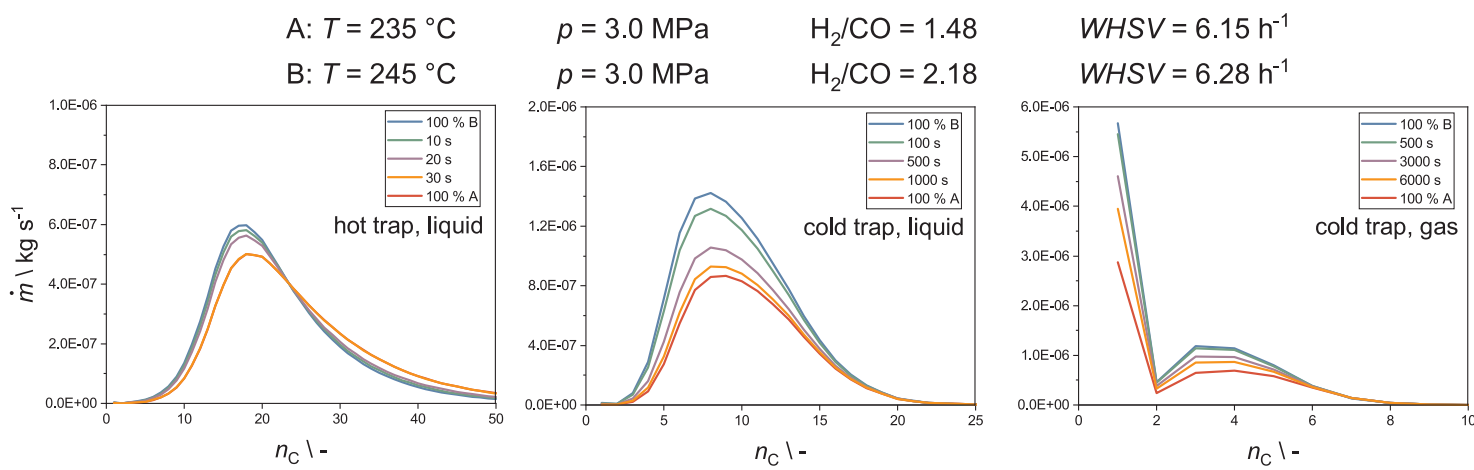

Fig. 12. Mass flow distributions according to the EOS flash model for (a) liquid phase in the HT (wax), (b) liquid phase in the CT (oil) and (c) residual gas phase for reaction conditions $\mathrm{A}$ and $\mathrm{B}$ and transitions between both conditions, applying the respective mixing time.

developed. This enabled time resolved calculations of product distribution in gas and liquid phase in all major parts of the test rig after condensation.

With an equation of state (VTPR-GCEOS), a significantly more reliable prediction of the phase equilibrium could be achieved, compared to ideal phase behavior assumptions. This was shown based on the coupling of reaction kinetics and flash calculation for description of the product separation in the different traps in steady state conditions compared with experimental results. The coupling of the reaction kinetics, flash and the RTD model was successfully implemented. By specifying input variables such as temperature, pressure and volume flow of the reactants, the prediction of reaction products, F-curves, fractional product separation, as well as flow and mixing properties could be achieved.

The determination of the VLE by means of EOS has contributed to considerable improvements in the modelling of the product in the traps. This is a further step towards the simulation of a load-flexible, dynamically operated FTS process. Further improvement would be the description of a time-resolved product separation from the traps, so that the quantity of products in the hot and cold trap can be determined at any time by varying the operating conditions.

The developed overall MATLAB ${ }^{\circledR}$ program provides satisfactory results and can be used as a first basis for controlling the operation of the FTS system in dynamic mode. A transferability to other reactor sizes and trap sizes is easily possible by adaptation of boundary conditions. Describing feed-flexible reaction, phase changes, condensation and changing pressure and temperature steps in general are important assets in any plant network. The presented model could be an important tool to meet the challenges of a decentralized PtL application with regard to volatile energy input.

\section{Funding source declaration}

The Vector Stiftung is acknowledged for financial support of parts of this work within the DynSyn project. Mr. Loewert was funded from this project during his $\mathrm{PhD}$.

\section{Declaration of Competing Interest}

The authors declare that they have no known competing financial interests or personal relationships that could have appeared to influence the work reported in this paper.

\section{References}

[1] J.M. Cullen, J.M. Allwood, The efficient use of energy: Tracing the global flow of energy from fuel to service, Energ. Policy 38 (2010) 75-81.

[2] Bundesministerium für Bildung und Forschung: Kopernikus Projekte, https://www. kopernikus-projekte.de/projekte/power-to-x, accessed 15 February 2020.

[3] F. Bauer, M. Sterner, Power-to-X im Kontext der Energiewende und des Klimaschutzes in Deutschland, Chem-Ing-Tech 92 (2020) 85-90.

[4] G.P. van der Laan, A.A.C.M. Beenackers, Kinetics and Selectivity of the FischerTropsch Synthesis: A Literature Review, Cataly. Rev. 41 (1999) 255-318.

[5] Institut für Mikroverfahrenstechnik (IMVT), https://www.imvt.kit.edu, accessed 15 February 2020.

[6] R. Myrstad, S. Eri, P. Pfeifer, E. Rytter, A. Holmen, Fischer-Tropsch synthesis in a microstructured reactor, Catal. Today (2009) 301-304.

[7] W. Bier, W. Keller, G. Linder, D. Seidel, K. Schubert, H. Martin, Gas to gas heat transfer in micro heat exchangers, Chem. Eng. Process. 33-43 (1993).

[8] R. Dittmeyer, T. Boeltken, P. Piermartini, M. Selinsek, M. Loewert, F. Dallmann, H. Kreuder, M. Cholewa, A. Wunsch, M. Belimov, S. Farsi, P. Pfeifer, Micro and micro membrane reactors for advanced applications in chemical energy conversion, Curr. Opin. Chem. Eng. 17 (2017) 108-125.

[9] P. Piermartini, T. Boeltken, M. Selinsek, P. Pfeifer, Influence of channel geometry on Fischer-Tropsch synthesis in microstructured reactors, Chem. Eng. J. 313 (2017) $328-335$.

[10] F.V. Vázquez, J. Koponen, V. Ruuskanen, C. Bajamundi, A. Kosonen, P. Simell, J. Ahola, C. Frilund, J. Elfving, M. Reinikainen, N. Heikkinen, J. Kauppinen, P. 
Piermartini, Power-to-X technology using renewable electricity and carbon dioxide from ambient air: SOLETAIR proof-of-concept and improved process concept, J. CO2 Util. 28 (2018) 235-246.

[11] S. LeViness, S.R. Deshmukh, L.A. Richard, H.J. Robota, Velocys Fischer-Tropsch Synthesis Technology—New Advances on State-of-the-Art, Top. Catal. 57 (2014) 518-525.

[12] S. LeViness, Opportunities for modular GTL in North America, Energy Frontiers, International (2012, 2012.).

[13] S. LeViness, Velocys Fischer-Tropsch Synthesis Technology Comparison to Conventional FT Technologies, San Antonio, Texas, 2013.

[14] M. Loewert, P. Pfeifer, Dynamically Operated Fischer-Tropsch Synthesis in PtL-Part 1: System Response on Intermittent, Feed, ChemEng. (2020).

[15] M. Loewert, M. Riedinger, P. Pfeifer, Dynamically Operated Fischer-Tropsch Synthesis - Part 2: Response on Photovoltaics, Data, ChemEng, 2020.

[16] M. Loewert J. Hoffmann P. Piermartini M. Selinsek R. Dittmeyer P. Pfeifer Microstructured Fischer-Tropsch reactor scale-up and opportunities for decentralized application Chem. Eng. Technol. 2202-2214 2019.

[17] H.S. Fogler Elements of chemical reaction engineering, 4 . 12. print ed., Prentice Hall, international series in the physical and chemical engineering sciences, Pearson Education Internat, Upper Saddle 2011 River, NJ.

[18] C. Sun (KIT), Direct syngas-to-fuel: integration of Fischer-Tropsch synthesis and hydrocracking in micro-structured reactors, Dissertation, Karlsruher Institut für Technologie 2018 Institut für Mikroverfahrenstechnik (IMVT), Karlsruhe.

[19] S.-H. Kwack, M.-J. Park, J.W. Bae, K.-S. Ha, K.-W. Jun, Development of a kinetic model of the Fischer-Tropsch synthesis reaction with a cobalt-based catalyst, Reac. Kinet. Mech. Cat. 104 (2011) 483-502.

[20] H. Eilers (KIT), Flexibler Betrieb der Fischer-Tropsch-Synthese - Katalysator- und Reaktorverhalten mit Co in der 3-Phasen-Blasensäule, Dissertation, Karlsruher Institut für Technologie 2018 Institut für Mikroverfahrenstechnik (IMVT), Karlsruhe.

[21] H. Pichler, H. Schulz, Neuere Erkenntnisse auf dem Gebiet der Synthese von Kohlenwasserstoffen aus CO und H2, Chem-Ing-Tech 42 (1970) 1162-1174.

[22] R.C. Brady, R. Pettit, Mechanism of the Fischer-Tropsch reaction. The chain propagation step, J. Am. Chem. Soc. 103 (1981) 1287-1289.

[23] W. Chen, I.A.W. Filot, R. Pestman, E.J.M. Hensen, Mechanism of Cobalt-Catalyzed CO Hydrogenation: 2, Fischer-Tropsch Synthesis, ACS Catal. 7 (2017) 8061-8071.

24] M. Zhuo, K.F. Tan, A. Borona, M. Saeys, Density Functional Theory Study of the CO Insertion Mechanism for Fischer-Tropsch Synthesis over Co Catalysts, J. Phys. Chem. C 113 (2009) 8357-8365.

[25] J. Schweicher, A. Bundhoo, N. Kruse, Hydrocarbon chain lengthening in catalytic CO hydrogenation: evidence for a CO-insertion mechanism, J. Am. Chem. Soc. 134 (2012) 16135-16138.

[26] P.H. Emmet, J.T. Kummer, H.H. Podgurski, W.B. Spencer, Mechanism Studies of the
Fischer-Tropsch Synthesis. The Addition of Radioactive Alcohol, J. Am. Chem. Soc. (1951) 564-569.

[27] P.H. Emmett, J.T. Kummer, Fischer-Tropsch Synthesis Mechanism Studies. The Addition of Radioactive Alcohols to the Synthesis Gas, J. Am. Chem. Soc. (1953) 5177-5183.

[28] C. Sun, Z. Luo, A. Choudhary, P. Pfeifer, R. Dittmeyer, Influence of the Condensable Hydrocarbons on an Integrated Fischer-Tropsch Synthesis and Hydrocracking Process: Simulation and Experimental Validation, Ind. Eng. Chem. Res. 56 (2017) 13075-13085.

[29] D.E. Mears, Diagnostic criteria for heat transport limitations in fixed bed reactors, J. Catal. 20 (1971) 127-131.

[30] D.E. Mears, Tests for Transport Limitations in Experimental Catalytic Reactors, Ind. Eng. Chem. Proc. DD. 10 (1971) 541-547.

[31] H. Hofmann Chemical Reactor Analysis and Design 2nd ed. 63, 1991 John Wiley \& Sons New York - Chichester.

[32] D. Vervloet, F. Kapteijn, J. Nijenhuis, J.R. van Ommen, Fischer-Tropsch reaction-diffusion in a cobalt catalyst particle: aspects of activity and selectivity for a variable chain growth probability, Catal. Sci. Technol. 2 (2012) 1221.

[33] J. Ahlers, J. Gmehling, Development of a Universal Group Contribution Equation of State. 2. Prediction of Vapor - Liquid Equilibria for Asymmetric Systems: Industrial \& Engineering Chemistry Research, Ind. Eng. Chem. Res. 41 (2002) 3489-3498.

[34] J. Ahlers, J. Gmehling, Development of a Universal Group Contribution Equation of State III. Prediction of Vapor - Liquid Equilibria, Excess Enthalpies, and Activity Coefficients at Infinite Dilution with the VTPR Model: Industrial \& Engineering Chemistry Research, Ind. Eng. Chem. Res. 41 (2002) 5890-5899.

[35] J. Ahlers J. Gmehling Development of an universal group contribution equation of state I. Prediction of liquid densities for pure compounds with a volume translated Peng-Robinson equation of state Fluid Phase Equilibr. 191 (2001).

[36] C.H. Twu, J.E. Coon, J.R. Cunningham, A new generalized alpha function for a cubic equation of state Part 1, Peng-Robinson equation, Fluid Phase Equilibr. 105 (1995) 49-59.

[37] J. Gmehling, B. Kolbe, M. Kleiber, J.R. Rarey, Chemical thermodynamics for process simulation, Wiley-VCH-Verl, Weinheim, 2012

[38] I.H. Bell, M. Satyro, E.W. Lemmon, Consistent Twu Parameters for More than 2500 Pure Fluids from Critically Evaluated Experimental Data, J. Chem. Eng. Data 63 (2018) 2402-2409.

[39] Y. Nannoolal, J. Rarey, D. Ramjugernath, Estimation of pure component properties, Fluid Phase Equilibr. (2007) 1-27.

[40] J.J. Marano, G.D. Holder, Characterization of Fischer-Tropsch liquids for vaporliquid equilibria calculations, Fluid Phase Equilibr. 138 (1997) 1-21.

[41] H. Schulz, Short history and present trends of Fischer-Tropsch synthesis, Appl. Catal. A-Gen. 186 (1999) 3-12. 